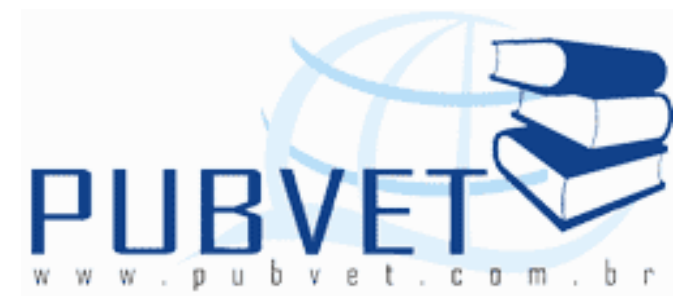

PUBVET, Publicações em Medicina Veterinária e Zootecnia.

\title{
Estratégias inovadoras no manejo de frangos de corte em avicultura industrial: fases pré-inicial, inicial, engorda e final
}

\section{Gerson Tavares Pessoa ${ }^{1 *}$, Gerlan Vieira de Sousa ${ }^{1}$, Maíra Soares Ferraz ${ }^{2}$, Matheus Levi Tajra Feitosa ${ }^{3}$, Acrísio de Miranda Sampaio ${ }^{4}$}

${ }^{1}$ Programa de Pós-graduação em Ciência Animal, Centro de Ciências Agrárias, Universidade Federal do Piauí, Teresina, Piauí, Brasil

${ }^{2}$ Campus Cinobelina Elvas, Universidade Federal do Piauí, Teresina, PI.

${ }^{3}$ Departamento de Morfofisiologia Veterinária, Universidade Federal do Piauí, Teresina, PI; PRODOC/CAPES

4 Departamento de Zootecnia, Centro de Ciências Agrárias, Universidade Federal do Piauí, Teresina, PI.

* Autor para correspondência, gersonpessoa@hotmail.com

\section{Resumo}

A partir da década de 60, o setor avícola brasileiro transformou-se em um verdadeiro complexo agroindustrial. Assim, o Brasil ocupa posição de destaque situando-se como o maior exportador e o terceiro maior produtor de carne de frango. Deve-se ressaltar que a avicultura brasileira é reconhecida hoje como uma das mais desenvolvidas do mundo, com índices de produtividade excepcionais, graças a programas de qualidade implementados em todos os elos da cadeia nos últimos anos. O manejo é de suma importância para o sucesso na criação de frangos de corte, além de outros aspectos que também 
são levados em consideração como melhoramento genético, nutrição e sanidade, mas, nenhum desses terá sucesso se não tiver um manejo bem feito. Dessa forma, objetivamos descrever as fases de criação (pré-inicial, inicial, engorda e final) em uma granja de avicultura industrial especializada na produção de frangos de corte. As técnicas de manejo empregadas na produção de frangos de corte nesta granja possibilitaram um rápido desenvolvimento e ganho de peso aos animais. Assim, estratégias como rotacionar comedouros, apagar e acender luzes, ligar e desligar ventiladores e os cuidados na fase préinicial jamais deverão ser esquecidas pelo avicultor. Além disso, medidas profiláticas como o uso de cloro, inseticidas, raticidas, cama aviária de ótima qualidade e o uso de antibióticos quando necessário reduzem a mortalidade, o desperdício de ração e proporciona maior lucratividade ao produtor avícola.

Palavras-chave: Manejo, frango de corte, avicultura.

\title{
Innovative strategies in the management of broiler chickens in poultry industry: phases pre-initial; initial; fattening and final
}

\begin{abstract}
From the 60s, the Brazilian poultry sector has become a real agroindustrial complex. Thus, Brazil occupies a prominent position standing as the largest exporter and third largest producer of chicken meat. It should be noted that the Brazilian poultry industry is recognized today as one of the world's most developed, with exceptional levels of productivity, thanks to quality programs implemented in all parts of the chain in recent years. The management is paramount for success in raising chickens, and other aspects are also taken into account as breeding, nutrition and health, but none of these will be successful if it does not management well done. Thus, we aimed to describe the phases (pre-starter, starter, fattening and final) in a poultry farm specializing in industrial production of broilers. Management techniques employed in the production of broiler farm this enabled a rapid development
\end{abstract}


PESSOA, G.T. et al. Estratégias inovadoras no manejo de frangos de corte em avicultura industrial: fases pré-inicial, inicial, engorda e final. PUBVET, Londrina, V. 7, N. 12, Ed. 235, Art. 1553, Junho, 2013.

and weight gain for animals. Thus, strategies such as feeders rotate, delete and turn lights on and off fans and care in the pre-starter should never be forgotten by the farmer. Furthermore, prophylactic measures such as the use of chlorine, insecticides, rodenticides, litter from excellent quality and the use of antibiotics when necessary to reduce mortality, waste feed and provides greater profitability by poultry producer.

Keywords: management, broiler, aviculture.

\section{Introdução}

No Brasil, ao longo da história, praticava-se a avicultura tradicional e familiar, também conhecida como produção de frango "caipira", produzida para o próprio consumo (LANA, 2000). Ainda segundo o mesmo autor, a principal região avícola do país era a Sudeste, até o começo da década de 70, predominantemente formada por empresas estabelecidas nas cidades de São Paulo, Rio de Janeiro e Belo Horizonte, as quais eram especializadas apenas na produção de matrizes.

O setor avícola de quatro a cinco décadas atrás era colocado em nosso país em um plano inferior e raras eram as granjas que apresentavam características de empreendimento industrial (ANDRIGUETTO, 1983).

As empresas avícolas além de terem que buscar eficiência através de fusões, aquisições, associações e parcerias, ainda tinham a necessidade de obter economia de escala e diversificar para diminuir riscos, entre outros aspectos (ALMEIDA, 2004).

As necessidades citadas acima levaram a avicultura industrial brasileira a passar por grandes transformações, a partir de 1970, cujos reflexos foram os aumentos contínuos do consumo de carne de frango no país (ALMEIDA, 2003).

O Brasil vem conquistando espaço significativo na produção mundial aumentou sua produção em cerca de $1000 \%$ entre os anos de 1961 a 2003, e assim, ocupa posição de destaque situando-se como o maior exportador e o 
terceiro maior produtor de carne de frango (ALBINO, 2000.; ALBINO, TAVERNARI; 2010). O Brasil encerrou o ano de 2009 produzindo cerca de 10,9 milhões de toneladas, o que representou $15,3 \%$ da produção mundial (UBA, 2009).

A evolução da avicultura brasileira deu-se principalmente com a introdução de materiais genéticos importados, especializados em produção de carne e ovos. Além do melhoramento genético, as áreas de sanidade, nutrição, ambiência e manejo contribuíram significativamente para que resultados positivos fossem alcançados (ROSÁRIO et al., 2004).

A avicultura é um dos setores mais importante do agronegócio brasileiro e também o que mais cresceu nos últimos anos, o Brasil em 2003, era o segundo maior produtor e exportador mundial em volume (ANUARIO BRASILEIRO, 2003).

O manejo na avicultura é de suma importância para o sucesso na criação de frangos, muitos aspectos também são levados em consideração como melhoramento genético, nutrição e sanidade, mas, nenhum desses teria sucesso se não fosse um manejo bem feito (LOBO, 2010).

Este trabalho teve por objetivo descrever as fases de criação em uma granja de avicultura industrial especializada na produção de frangos de corte, com o intuito de fornecer importantes informações aos pequenos e médios produtores, com vistas a minimizar possíveis erros de manejo em suas criações.

\section{Material e Métodos}

Os dados utilizados neste estudo foram provenientes de uma granja situada no Município de Altos, microrregião de Teresina, Piauí, Brasil. Galpões de criação

A granja possui cinco aviários todos construídos no sentido lesteoeste, com capacidade para alojar até 136000 aves. 
A área onde os galpões estão construídos é nivelada possuindo $8 \mathrm{~m}$ a mais nas laterais e $10 \mathrm{~m}$ na frente e no fundo do galpão. A extensão de $8 \mathrm{~m}$ nas laterais é devido à necessidade de tráfego de caminhões para o carregamento dos frangos e escoamento da água quando da limpeza e desinfecção dos galpões. Já a área de $20 \mathrm{~m}$, para frente e para trás, é justificada pela construção de um telheiro, o qual serve para proteção contra a incidência de raios solares e chuvas.

Os galpões demonstram diferentes características entre si que refletem claramente como a granja evoluiu ao longo dos anos, seja pelo aumento do nível tecnológico, pelas adaptações a legislação em vigor, bem como pela aquisição de equipamentos de primeira linha. Ambos os galpões são bem iluminados, devido à existência de um excelente sistema de iluminação composto por lâmpadas fluorescentes. São forrados com plástico de cor azul e amarelo, e possuem pé direito com altura média de 2,5m. A granja possui cinco galpões enumerados de 1 a 5 , onde são mostrados na tabela 1 as dimensões e respectivas áreas totais de cada galpão.

Tabela 1 - Dimensão e área total dos galpões de criação de frango de corte da granja, Altos PI - 2011.

\begin{tabular}{ccc}
\hline Galpão & Dimensão $\mathbf{( m )}$ & $\begin{array}{c}\text { Área Total } \\
\left(\mathbf{m}^{\mathbf{2}} \mathbf{)}\right.\end{array}$ \\
\hline 01 & $10,30 \times 130,15$ & 1340,54 \\
02 & $11 \times 150,05$ & 1650,55 \\
03 & $12,04 \times 151,07$ & 1818,88 \\
04 & $11,83 \times 159,40$ & 1885,70 \\
05 & $11,65 \times 159,74$ & 1860,97 \\
\hline
\end{tabular}

Os galpões 1 e 2 são os mais antigos da granja e contam com caixas d'água de fibra com capacidade para 1000 d'água para abastecimento dos bebedouros pendulares. Além disso, cada aviário dispõe de uma caixa d'água de fibra para o sistema de nebulização. Ambos os galpões são telados com tela de espessura de duas polegadas e fio 12 . O chão é cimentado e possui 
PESSOA, G.T. et al. Estratégias inovadoras no manejo de frangos de corte em avicultura industrial: fases pré-inicial, inicial, engorda e final. PUBVET, Londrina, V. 7, N. 12, Ed. 235, Art. 1553, Junho, 2013.

declividade de $3 \%$ para que quando realizada a lavagem e desinfecção a água possa escorrer pelas laterais. Apresentam ventilação positiva, sendo que o galpão 1 possui 21 ventiladores e o galpão 2 possui 32 ventiladores. Estes são forrados e possuem sistema de cortinas trançadas com plástico da cor azul. 0 galpão 1 e 2 possuem três linhas de comedouros automáticos, contudo o aviário 1 têm 585 comedouros e o 2 possui 666. Esta diferença é devido ao fato do galpão 2 ser maior que o 1 .

O galpão 3 é diferenciado em praticamente todos os sentidos, principalmente pelo fato de ser totalmente automático e facilmente controlável pelo seu centro de comando. Apresenta ventilação negativa, isto é, possui exaustores distribuídos em quatro grupos, sendo dois grupos de três exautores de comando alternado localizado na parede ao fundo do galpão e dois grupos de dois exaustores localizados nas paredes laterais ao fundo do galpão. O uso de exaustores promove uma economia no consumo de energia elétrica, haja vista que cada exaustor consome cerca de $1 \mathrm{CV}$ dia e 1 ventilador consome em torno de 0,5CV dia. Conta com o auxílio de sensor de temperatura, essencial quando da falta de energia elétrica, pois após três minutos da falta desta as lonas abaixam automaticamente. Possui duas caixas d'água destinada ao abastecimento dos bebedouros, uma com capacidade para armazenar $3000 \mathrm{~L} \mathrm{e}$ outra com capacidade para 500L para facilitar eventuais medicações às aves. Além dessas possui uma caixa d'água de fibra para o sistema de nebulização interno e externo. O galpão contém 696 comedouros automáticos, tela de arame fio 12 e malha de duas polegadas.

Os galpões 4 e 5 são os mais novos constituintes da granja e já aparecem com modificações importantes a criação de frangos. A principal diferença desses galpões para os demais é relacionada à tela de proteção, pois esta é de borracha e tem uma espessura bem reduzida quando comparada a dos outros três galpões anteriormente descritos. Esta mudança é pelo fato da Instrução Normativa no 56, de 4 de dezembro de 2007, que integra o Programa Nacional de Sanidade Avícola do Ministério da Agricultura, Pecuária e 
Abastecimento - MAPA, estabelecer alterações aos estabelecimentos que desempenha a atividade avícola. Esta é uma medida necessária, pois com esta tela a entrada de pássaros é muito dificultada, o que evita possíveis contaminações e proliferação de doenças. Possui ventilação positiva com 33 ventiladores cada, o que pode se afirmar que são galpões econômicos diferentemente do que é visto no galpão 2 que possui menores dimensões e conseqüentemente menor área total. Quanto ao número de comedores automáticos estes são de 737 para o galpão 4 e 746 para o galpão 5 . Em todos os galpões os comedores podem ser suspensos quando da limpeza e desinfecção, o que facilita o manejo.

As linhagens utilizadas neste ciclo foram ROSS e COBB, sendo 25000 pintinhos COBB e 106640 pintinhos ROSS (Tabela 2). Os pintos foram vacinados no incubatório da COAVE (Cooperativa que a granja integra) contra a doença de Marek e aos 10 dias de idade contra as doenças de Gumboro e Newcastle, via oral, água de bebida. Em todas as fases de produção de frango de corte a ração apresentou níveis de proteína bruta e energia metabolizável superiores aos valores relatados por Soares (2003) em outra granja que integra a COAVE. Este fato demonstra a evolução quanto ao caráter nutricional da dieta nutricional das aves.

Tabela 2 - Número de aves alojadas, linhagem e estimativa de mortalidade/dia por lote de frango de corte na granja. Altos - PI 2011.

\begin{tabular}{cccc}
\hline Lotes & $\begin{array}{c}\text { No de aves } \\
\text { alojadas }\end{array}$ & $\begin{array}{c}\text { Estimativa de } \\
\text { Mortalidade/dia }\end{array}$ & Linhagem \\
\hline Lote 01 & 21000 & 21 & ROSS \\
Lote 02 & 25000 & 25 & ROSS \\
Lote 03 & 30000 & 30 & ROSS \\
Lote 04 & 25000 & 25 & COBB \\
Lote 05 & 30640 & 30,64 & ROSS \\
\hline Total & $\mathbf{1 3 1 6 4 0}$ & $\mathbf{1 3 1 , 6 4}$ & \\
\hline Média & & $\mathbf{2 6 , 3 2 8}$ & \\
\hline
\end{tabular}




\section{Manejo na Produção de Frangos de Corte}

Manejo no recebimento dos pintos de um dia

$\mathrm{Na}$ chegada dos pintinhos todos os equipamentos estavam à espera para recebê-los, inclusive jornais sobre a casca de arroz. Neste é colocado um pouco de ração para que o acesso ao alimento seja mais fácil. No dia seguinte os jornais são retirados para evitar algum tipo de contaminação. As aves são distribuídas em quatro seções e estas formam o pinteiro. A distribuição das aves ocorre de tal forma que cada seção do pinteiro tenha a mesma quantidade de aves, favorecendo a uniformidade dos lotes. São colocados 65 pintos por metro quadrado no primeiro dia de alojamento. Os bebedouros do tipo pendular já estão com água e muito perto do solo para não provocar jejum hídrico.

Manejo na fase pré-inicial

O pinteiro é construído no meio do galpão, local onde também se situa a campânula, e a partir daí é realizada a construção das seções e formação completa do pinteiro. O material usado como anteparo para a divisão das seções são folhas de madeira prensada, material leve, lavável, de fácil acesso e desinfecção e grande durabilidade. A partir do segundo dia começou a realização dos aumentos, fato necessário, devido ao crescimento do pinto. Tal aumento foi feito a partir do desenvolvimento do pinto. A abertura de espaço foi realizada diariamente e de forma gradativa, visando sempre à conservação da qualidade da cama e melhora diária na relação de equipamentos para aves. O tamanho acrescido a partir do segundo dia foi de $1,5 \mathrm{~m}$ para cada seção e a partir do sexto dia foram adicionados $0,25 \mathrm{~cm}$ a medida, que totalizou um acréscimo de $1,75 \mathrm{~m}$ em cada seção.

Os cuidados foram maiores nos primeiros vinte dias de idade, onde 0 manejo das cortinas e a utilização de sobrecortinas nos galpões se tornaram necessários para uma vedação e controle térmico adequado. O uso adequado 
PESSOA, G.T. et al. Estratégias inovadoras no manejo de frangos de corte em avicultura industrial: fases pré-inicial, inicial, engorda e final. PUBVET, Londrina, V. 7, N. 12, Ed. 235, Art. 1553, Junho, 2013.

de campânulas e a utilização de "casulos" (cortina divisória no pinteiro) para aumentar a concentração de calor foi uma prática reconhecidamente eficaz no controle térmico, redução da mortalidade inicial, da desuniformidade do lote e dos casos de Síndrome Ascítica.

Nesta fase utilizam-se comedouros tubulares infantis com ração préinicial Quali Feed ${ }^{\circledR}, 200 \mathrm{~g}$ (Tabela 4), e após quatro dias começa o uso dos comedouros Tubo Flex Agromarau ${ }^{\circledR}$, porém estes não são ligados de forma automática, mas são utilizados de forma manual ofertando a ração pré-inicial nos comedouros tubulares infantis e nos comedouros Tubo Flex Agromarau ${ }^{\circledR}$, o que favorece o crescimento do pinto. O motivo para a não disponibilidade de ração nos três primeiros dias de vida do pinto nestes comedouros é porque as aves correm o risco de entrar no comedouro e não sair, comprometendo a ingestão de água e contribuindo para o aumento do estresse aos animais.

A proporção na formação do pinteiro de comedouros e bebedouros é 1 para 60. Porém, com o passar dos dias (cinco dias) o número de bebedouros é reduzido gradativamente e o número de comedouro é ampliado, devido ao uso dos comedouros Tubo Flex Agromarau ${ }^{\circledR}$.

A substituição de um tipo de comedouro por outro ocorre de forma cuidadosa e gradativa, de forma que, as aves se habituem a consumir ração dos comedouros automáticos, haja vista que nos primeiros cinco dias de vida consomem ração apenas em comedouros infantis. A disponibilidade de ração em comedouros tubulares e comedouros tuboflex são com o propósito de ofertar maior quantidade de alimento e para que ocorra a mudança crescente de comedouro infantil para tuboflex, mitigando a dificuldade de alcançar a ração, o que é visto pela introdução dos comedouros automáticos a partir dos primeiros dias de vida.

Quanto ao preenchimento, este deve não ser cheio por completo, pois, devido ao fato dos pintinhos serem novos, o consumo de ração é pequeno. Desta maneira, evita-se que a ração permaneça por dois ou três dias, o que compromete sua qualidade. Lembrando sempre que o prato foi 
PESSOA, G.T. et al. Estratégias inovadoras no manejo de frangos de corte em avicultura industrial: fases pré-inicial, inicial, engorda e final. PUBVET, Londrina, V. 7, N. 12, Ed. 235, Art. 1553, Junho, 2013.

mexido inúmeras vezes no decorrer do dia, pois se usava ração triturada e peletizada Quali Feed ${ }^{\circledR}$ com 24,33\% de proteína bruta e 3029 Kcal de energia metabolizável por $\mathrm{Kg}$ de ração, sendo que esta prática facilitava a descida da ração do tubo para o prato.

Na fase pré-inicial a mola responsável pela saída de água é apertada ao máximo, com o intuito de ofertar ao pintinho a maior quantidade de água possível, o que implica relatar que quanto maior o consumo de água maior será o consumo de ração. À medida que os dias vão passando e os pintinho vão crescendo essa mola é folgada e a quantidade de água é reduzida aos poucos até que esta esteja folgada por completa. Tal ajuste depende do manejador, porém no período de observação verificou-se que tal ajuste foi iniciado por volta do $9^{\circ}$ dia. Lembramos que na fase pré-inicial a proporção de bebedouros é de 1 bebedouro para cada 60 pintinhos e que no $8^{\circ}$ dia estes são retirados e ficam apenas os das linhas normais de água. Quanto à altura dos bebedouros na fase inicial este é bem próximo do solo, mas não chega a tocálo e à medida que os pintinhos vão se desenvolvendo até a fase de acabamento a altura dos bebedouros vai acompanhando a altura do dorso das aves.

\section{Manejo na fase inicial}

Fase que compreende o intervalo entre o oitavo e o vigésimo primeiro dia de idade. É ofertada aproximadamente $1 \mathrm{Kg}$ de ração (Tabela 4) com $22,37 \%$ de proteína bruta e 3220Kcal de energia metabolizável por $\mathrm{Kg}$ de ração.

A pulverização com cloro é feita com Aviclor pulverização ${ }^{\circledR}$. Os bebedouros são regulados constantemente e os comedouros são rotacionados diariamente. Tanto nesta fase como na fase pré-inicial usam-se comedouros tubulares infantis para que as aves tenham maior disponibilidade de alimento. A remoção dos comedouros infantis ocorre de forma gradativa, removendo-se $1 / 3$ a cada dia. Neste ciclo a retirada ocorreu nos dias $19^{\circ}, 20^{\circ}$ e $21^{\circ}$, pois as 
aves estavam com baixo ganho de peso (Tabela 3) e na tentativa de melhorar o desempenho das aves o tempo de permanência dos comedouros tubulares infantis foram prolongados.

Quanto à utilização das lâmpadas estas eram ligadas ao anoitecer e desligadas ao amanhecer. O uso dos ventiladores era de forma alternada e melhorado com o uso das cortinas, formando um sistema de ventilação em túnel.

Nesta fase foi observado um grande aumento no número de aves mortas. Tal fato ocorreu por causa de uma reação vacinal no trato respiratório das aves. Para contornar esta situação foi administrado $20 \mathrm{mg}$ de antibiótico, enrofloxacina, Enrofloxacina ${ }^{\circledR}$, na água de bebida, uma vez ao dia durante dez dias. Foram realizadas várias necropsias e constatou-se um aglomerado celular na cavidade torácica corroborando a hipótese de reação vacinal, a qual ocorreu entre os dez primeiros dias de vida.

No $18^{\circ}$ dia foi feita uma vacinação contra doença de Gumboro para proteção e estimulo do sistema imunológico.

Nesta fase os galpões já estavam repletos e não é feita mais a abertura de espaço, no galpão 01 são alojadas 15,66 aves $/ \mathrm{m}^{2}$, no galpão 02 15,14 aves/m², no galpão 0316,49 aves/m², no galpão 0413,25 aves/m² e no galpão 0516,46 aves $/ \mathrm{m}^{2}$.

\section{Manejo na fase de engorda}

Fase que possui duração de 16 dias e está compreendida entre o vigésimo segundo e o trigésimo sétimo dia. Nesta fase é oferecida a cada ave aproximadamente $2,2 \mathrm{Kg}$ de ração (Tabela 4) contendo $20,14 \%$ de proteína bruta e 3299 Kcal de energia metabolizável por Kg de ração. Apresenta como característica marcante o baixo nível de mortalidade.

Os bebedouros são lavados uma vez ao dia no período da manhã e os comedouros são girados cuidadosamente porque caso estes sejam rotacionados com muita força irá desperdiçar ração. 
Nesta fase como artifício para ganho de peso os ventiladores são desligados por 15 minutos e, em seguida ligados novamente. Esta prática é feita inúmeras vezes durante o dia, pois a ave se habitua e começa a ficar condicionada, ingerindo ração que normalmente não iria consumir.

Outra alternativa é desligar as luzes a noite por cerca de 15 minutos, com o propósito de deixar todos os animais quietos e após as lâmpadas serem acesas as aves irem consumir a ração. De igual forma essa outra técnica pode ser realizada constantemente. O manejo das cortinas é associado ao uso de nebulizadores e ventiladores. As lâmpadas são ligadas ao anoitecer e desligadas ao entardecer.

O cloro era utilizado na água de bebida e no sistema de nebulização para melhorar o ar contido no galpão.

Manejo na fase final

Fase que dura aproximadamente oito dias e compreende o intervalo entre o trigésimo oitavo dia até o quadragésimo quinto dia. Nesta etapa de criação é ofertada a cada ave aproximadamente $1 \mathrm{Kg}$ de ração (Tabela 4), que contém $18,59 \%$ de proteína bruta e $3340 \mathrm{Kcal}$ de energia metabolizável por $\mathrm{Kg}$ de ração.

Durante essa fase o principal cuidado é referente à temperatura ambiente, pois como as aves já estão com peso superior a $2 \mathrm{Kg}$ (Tabela 3 ) o estresse térmico é grande. Contudo, para resolução deste problema é feito o manejo de cortinas associado com o uso de todos os ventiladores ligados mais o sistema de nebulização nas horas mais quentes do dia. Uma prática adotada para reduzir os níveis de mortalidade nesta fase é a retirada dos frangos folgando as seções onde estão as aves, isto é, em vez de retirar as aves por seção, retiram-se aves de todas as seções, de tal forma que a densidade de aves diminua e proporcione maior conforto.

No decorrer desta fase os bebedouros são lavados uma vez ao dia no período da manhã e os comedouros automáticos são rodados duas vezes no 
período da manhã e três vezes no decorrer da tarde com o propósito de estimular as aves a consumirem a ração. A noite, o trabalho dos funcionários da granja é direcionado a movimentação dos comedouros, pois a temperatura é mais baixa e as aves consomem mais ração. Nesta fase espera-se que o número de aves mortas seja superior ao número de aves mortas na fase de engorda, devido ao fato dos bebedouros estarem sempre sendo levantados para que estejam na altura do dorso do animal, evitando que caia água na cama e ocasione problemas como coccidioses. A monitoria sanitária era feita com o uso de cloro na água de bebida (Aviclor choque ${ }^{\circledR}$ ) 50g para cada 350 L de água. As lâmpadas são ligadas ao anoitecer e desligadas ao entardecer.

Tabela 3 - Acompanhamento do ganho de peso dos lotes de frango de corte da granja, Altos - PI - 2011.

\begin{tabular}{|c|c|c|c|c|c|c|}
\hline $\begin{array}{c}\text { Data da } \\
\text { Pesagem }\end{array}$ & Lote 01 & Lote 02 & Lote 03 & Lote 04 & Lote 05 & Média \\
\hline $\begin{array}{c}10 \\
\text { Pesagem } \\
\text { (7 dias) }\end{array}$ & $195 \mathrm{~g}$ & $190 \mathrm{~g}$ & $195 \mathrm{~g}$ & $190 \mathrm{~g}$ & $188 \mathrm{~g}$ & $191,6 \mathrm{~g}$ \\
\hline $\begin{array}{c}20 \\
\text { Pesagem } \\
\text { (14 dias) }\end{array}$ & $488 \mathrm{~g}$ & $420 \mathrm{~g}$ & $445 \mathrm{~g}$ & $450 \mathrm{~g}$ & $440 \mathrm{~g}$ & $448,6 \mathrm{~g}$ \\
\hline $\begin{array}{c}30 \\
\text { Pesagem } \\
\text { (21 dias) }\end{array}$ & $900 \mathrm{~g}$ & $846 \mathrm{~g}$ & $890 \mathrm{~g}$ & $905 \mathrm{~g}$ & $880 \mathrm{~g}$ & $884,2 \mathrm{~g}$ \\
\hline $\begin{array}{c}40 \\
\text { Pesagem } \\
\text { (28 dias) }\end{array}$ & $1420 \mathrm{~g}$ & $1350 \mathrm{~g}$ & $1430 \mathrm{~g}$ & $1415 \mathrm{~g}$ & $1400 \mathrm{~g}$ & $1403 \mathrm{~g}$ \\
\hline $\begin{array}{c}50 \\
\text { Pesagem } \\
\text { (35 dias) }\end{array}$ & $2020 \mathrm{~g}$ & $1920 \mathrm{~g}$ & $1930 \mathrm{~g}$ & $2015 \mathrm{~g}$ & $2030 \mathrm{~g}$ & $1983 \mathrm{~g}$ \\
\hline
\end{tabular}

Manejo na retirada dos lotes

O avicultor é avisado com certa antecedência sobre a saída do frango para que ele possa comunicar a equipe de funcionários da granja, procurar outras pessoas para ajudar na retirada das aves e informar ao encarregado a quantidade de aves que irão sair e o peso médio estipulado pelo mercado. 
O método de apanha das aves deve proporcionar menores perdas de peso, desidratação no transporte, e propiciar condições de bem estar aos animais. Na granja observada o método de apanha das aves utilizado foi o de conter fisicamente a ave pelo pescoço e em seguida levá-la a sacola. Para isso, as aves são cercadas com folhas de Eucatex ${ }^{\circledR}$, o que proporcionar agilizar 0 processo e causar menos transtornos aos funcionários e as aves. Este método não causa traumatismos aos animais o que beneficia o produtor, ocasionando uma menor perca de animais a serem comercializados.

Outro dado que é anotado criteriosamente e com muita atenção na ficha de acompanhamento é a quantidade de ração que é ofertada, o que facilita a visualização da relação: ganho de peso versus conversão alimentar. São anotados o tipo de ração, a quantidade de ração e o lote de destino (Tabela 4).

Tabela 4 - Tipo e quantidade de ração fornecida aos lotes de frango de corte da granja, Altos - PI - 2011.

\begin{tabular}{ccccccc}
\hline Tipo & Lote $\mathbf{0 1}$ & Lote 02 & Lote 03 & Lote 04 & Lote 05 & Total \\
\hline Pré-Inicial & $4200 \mathrm{Kg}$ & $5000 \mathrm{Kg}$ & $6000 \mathrm{Kg}$ & $5000 \mathrm{Kg}$ & $6000 \mathrm{Kg}$ & $26200 \mathrm{Kg}$ \\
Inicial & $21000 \mathrm{Kg}$ & $25000 \mathrm{Kg}$ & $30000 \mathrm{Kg}$ & $25000 \mathrm{Kg}$ & $30000 \mathrm{Kg}$ & $131000 \mathrm{Kg}$ \\
Engorda & $45000 \mathrm{Kg}$ & $51000 \mathrm{Kg}$ & $63000 \mathrm{Kg}$ & $51000 \mathrm{Kg}$ & $66000 \mathrm{Kg}$ & $276000 \mathrm{Kg}$ \\
Final & $23500 \mathrm{Kg}$ & $26500 \mathrm{Kg}$ & $26500 \mathrm{Kg}$ & $17500 \mathrm{Kg}$ & $26000 \mathrm{Kg}$ & $120000 \mathrm{Kg}$ \\
\hline Total & $93700 \mathrm{Kg}$ & $107500 \mathrm{Kg}$ & $125500 \mathrm{Kg}$ & $98500 \mathrm{Kg}$ & $128000 \mathrm{Kg}$ & $\mathbf{5 5 3 2 0 0 K g}$ \\
\hline
\end{tabular}

\section{Conclusão}

As técnicas de manejo empregadas na produção de frangos de corte nesta granja possibilitaram um rápido desenvolvimento e ganho de peso aos animais. Estratégias como rotacionar comedouros, apagar e acender luzes, ligar e desligar ventiladores e os cuidados na fase pré-inicial jamais deverão ser esquecidas pelo avicultor, bem como pelos funcionários responsáveis pela 
PESSOA, G.T. et al. Estratégias inovadoras no manejo de frangos de corte em avicultura industrial: fases pré-inicial, inicial, engorda e final. PUBVET, Londrina, V. 7, N. 12, Ed. 235, Art. 1553, Junho, 2013.

rotina administrada nos galpões de criações. Medidas profiláticas como o uso de cloro, inseticidas, raticidas, cama aviária de ótima qualidade e o uso de antibióticos quando necessário reduzem a mortalidade, o desperdício de ração e proporciona maior lucratividade ao produtor avícola.

\section{Referências}

ALBINO, L. F. T. Conceito de proteína ideal na formulação de dietas para frangos de corte. Revista CFMV, Brasília-DF, Ano XVI, n.49, p. 68-72, 2010.

AlBino, L. F. T.; TAVERnARI, F. C. Produção e manejo de frangos de corte. Viçosa, MG: Editora UFV, 2010.

ALMEIDA, L. DA S. Competitividade de empresas de abate e processamento de frangos da cadeia avícola do oeste do Paraná: uma análise sob a ótica da Swto. Lavras: UFLA, 2004. p. 91.

ALMEIDA, R. A. Identidade, distinção e territorialização: o processo de (re) criação camponesa no Mato Grosso do Sul. 2003. 391f. Tese (Doutorado em Geografia.). Faculdade de Ciências e Tecnologia, Universidade Estadual Paulista, Presidente Prudente, São Paulo, 2003.

ANDRiguetTO, J. M. et al. Nutrição Animal. Ed. Nobel, $2^{\circ}$ ed. São Paulo, 1983. p. 395.

LANA, G. R. Q. Avicultura. Ed. Rural. Recife: UFRPE, 2000. 237p.

LOBO, R. R.; GARCIA, R. G.; BELLONI, M.; FRANCISCO, N. S; LIMA, N. D. S., FELIX, G. A. Manejo das Instalações para Frangos de Corte. 2010.

ROSÁRIO, M. F.; SILVA, M. A. N.; COELHO, A. A. D.; SAVINO, V. J. M. S. Síndrome ascítica em frangos de corte: uma revisão sobre a fisiologia, avaliação e perspectivas. Ciência Rural, Santa Maria, v. 34, n. 6, p. 1987-1996, 2004.

SOARES, L. S. Manejo de frango de corte na granja Renascer da COAVE (Cooperativa Mista dos Avicultores do Piauí) Teresina-PI. Universidade Federal do Piauí, Teresina, 2003. p. 26-38.

UBA - União Brasileira de Avicultura. Protocolo de Boas Práticas de Produção de Frango. São Paulo, 2009. 